\title{
Microbiomes from feces vs. gut in tadpoles: distinct community compositions between substrates and preservation methods
}

\author{
Sten Anslan ${ }^{1}$, Huan Li² ${ }^{2}$, Sven Künzel ${ }^{3}$ \& Miguel Vences ${ }^{1}$
}

\author{
1) Zoological Institute, Technische Universität Braunschweig, Mendelssohnstr. 4, 38106 Braunschweig, Germany \\ ${ }^{2)}$ Institute of Occupational Health and Environmental Health, School of Public Health, Lanzhou University, Lanzhou 730000, China \\ ${ }^{3)}$ Department of Evolutionary Genetics, Max Planck Institute for Evolutionary Biology, Plön, Germany \\ Corresponding author: STEN ANSLAN, e-mail: s.anslan@tu-braunschweig.de
}

Manuscript received: 12 January 2020

Accepted: 2 December 2020 by STEFAN LöTTERS

\begin{abstract}
Sample type and preservation methods are likely to influence the results of microbiome analyses. Here, we sampled tadpoles of Nanorana parkeri non-invasively for feces, and subsequently for hindgut through dissection. Gut and fecal samples were stored in ethanol, and additionally, part of the gut samples were frozen, but temporarily thawed during transport as it often happens under difficult field conditions. Our results showed that both substrate (gut vs. feces) as well as preservation method can influence the analysis of intestinal microbiomes. Frozen gut samples strongly differed from ethanol-stored samples, and most of the frozen samples were dominated (in relative abundance) by a set of Proteobacteria OTUs that were completely absent from the ethanol-stored samples. This blooming of contaminant bacteria occurred after less than $12 \mathrm{~h}$ of thawing, thus caution should be taken when constancy of cold temperatures cannot be maintained in the field for sample preservation purposes. Among ethanol-stored samples, whereas the recovered bacterial richness and phylogenetic diversity did not differ, the community structure varied significantly. Thus, for meaningful gut microbiome meta-analyses it is important to acknowledge the effect of the sampling substrate for the microbial community composition.
\end{abstract}

Key words. Amphibia, Anura, Nanorana parkeri, gut microbiota, fecal samples, metabarcoding, 16S rRNA gene.

\section{Introduction}

Many studies have targeted the composition, dynamics and highlighted the health relevance of the human gut microbiome (e.g. Clemente et al. 2012, Tuddenham \& Sears 2015). Likewise, animal-associated microbial communities play important roles in the biology and health of their hosts (McFALL-NGAi et al. 2013), including food degradation and energy harvest (Tremaroli \& BÄCKHed 2012), immunity regulation (ROUND \& MAZMANIAN 2009), and physical development (SOMMER \& B̈̈CKHED 2013). These studies are typically based on high-throughput sequencing (HTS) of short 16S rRNA gene amplicons, where significantly different composition and diversity patterns of the host-associated microbiomes are driven by host taxonomy, ecology and environment (Engel \& Moran 2013, KoHL et al. 2014, Shapira 2016, Vences et al. 2016, Lyra et al. 2018, REESE \& DUNN 2018).

While the intestinal microbiome of mammals has been the subject of numerous studies (e.g. Li et al. 2016a, 2016b, SonNENBURG et al. 2016), research on microbiomes associated with amphibians is still in its infancy. Work on this vertebrate group has typically focused on the cutane- ous microbiome (McKenzIE et al. 2012, Kueneman et al. 2019), often in the context of its effects on pathogenic fungi causing amphibian declines (BLETZ et al. 2013, WALKE \& BELDEN 2016). In particular, work on the amphibian gut microbiome is scarce (BLETZ et al. 2016, WENG et al. 2016, KnUtie et al. 2017, Fontaine et al. 2018, HuAng et al. 2018, LYRA et al. 2018, WIEBLER et al. 2018) but of substantial biological interest especially in frogs, given the drastic restructuring of the gut during metamorphosis from a largely herbivorous tadpole to an exclusively carnivorous frog (КоHL et al. 2013, Vences et al. 2016).

Understanding which factors influence microbiomes at local and global scale is of importance to unravel general biogeographic and macro-ecological trends (AMEND et al. 2013, BAHram et al. 2018b, Kueneman et al. 2019) and host-microbiome interactions (REESE \& DUNN 2018), including diseases. Sampling the microbiome of the intestine is a moderately to strongly invasive approach, especially in small animals where it requires killing the studied individuals. Instead, samples of fresh feces are often used and the fecal microbiome is considered as representative of the gut microbiome (e.g. ReEse \& DunN 2018, Zierer et al. 2018). However, indications exist that fecal character- 
istics influence the composition and richness of detected microbiota (FALONY et al. 2018). Therefore, it is uncertain to which extent the fecal microbiome may serve as proxy for the gut microbiome across hosts, and whether communities from feces and gut samples are fully comparable (e.g. ERICSSON et al. 2018). In particular, only few studies address this question in tadpoles (Song et al. 2018).

For large-scale analyses, especially meta-analyses of data sets originating from a diversity of sources, comparability of data is a basic prerequisite. This refers not only to laboratory methods but also extends to sampling and sample preservation (FRICKER et al. 2019). Thus, a further factor influencing the inference of microbiome composition from high-throughput sequencing of amplicons is the method of sample preservation. Freezing samples at $-20^{\circ} \mathrm{C}$ immediately upon collection has been defined as the gold standard to ensure the microbial community does not change until DNA extraction (SoNG et al. 2016). Keeping samples uninterruptedly at this temperature is however not always possible under difficult field conditions, which might lead to alterations of the microbial community composition during episodes of thawing (CHOO et al. 2015).

In our study, we tested the effect of sampling substrate, feces $v s$. hindgut, to characterize the gut microbiota of tadpoles of the High Himalaya frog (Nanorana parkeri, Dicroglossidae). In addition, we compared the similarity of the detected microbiota using freezing $v s$. ethanol (EtOH) preservation method of the samples from the same specimens. The sample types per specimen included EtOHstored feces, EtOH-stored gut and frozen gut samples. As feces samples are widely considered to reflect gut microbiota, we expected similar richness and community patterns from the $\mathrm{EtOH}$-stored feces and gut samples. In this study, the frozen gut samples were exposed to thawing episodes during sample transport from the remote location, thus we predicted a skewed microbial community composition in comparison with EtOH-stored gut samples and tested the extent and constancy of this effect.

\section{Methods \\ Study site and sampling methods}

Tadpoles of Nanorana parkeri in Gosner stages (GosNer 1960) 26-30 were collected on 2 July 2018 from the central Qinghai-Tibetan Plateau, China, in a small pond directly nearby a small tributary stream, in the area of Lake Nam Co $\left(30.82840^{\circ} \mathrm{N}, 91.06397^{\circ} \mathrm{E} ; 4,740 \mathrm{~m}\right.$ above sea level). Tadpoles were collected using dip nets and placed individually into sterile Whirl-Pak bags together with a small amount of clean water from the respective water bodies. A pond water control sample was collected by dipping a sterile swab into the water, placing it into a cryotube and freezing it (list of taxa found from pond water are outlined in Supplementary Table $S_{1}$ ). Specimens were kept overnight (ca. $14 \mathrm{~h}$ ) in the bags, anesthetized with tricaine methanesulfonate (MS222; Sigma-Aldrich, St. Louis, MO, USA) solution and subsequently overdosed using MS222. Sacrific- ing of the specimens was reported to the animal welfare officer of Technische Universität Braunschweig in compliance with German animal welfare law, section 4(3). We collected the feces accumulated in the bags using pipettes, as well as a portion of hindgut of every individual. In summary, we obtained three replicate samples per specimen: (1) feces, stored in 96\% EtOH; (2) hindgut, stored in $96 \%$ EtOH; (3) hindgut, frozen at $-20^{\circ} \mathrm{C}$ right after collection (Fig. 1). Samples were frozen upon collection, but as typical for suboptimal fieldwork conditions, underwent two thawing-freezing cycles during transport to the lab, with temperatures of $10-15^{\circ} \mathrm{C}$ for a limited time $(<12 \mathrm{~h}$ each time). In the laboratory, all samples were stored at $-20^{\circ} \mathrm{C}$ until further processing.

\section{Molecular analysis}

Following the manufacturer's instructions, DNA was extracted using a DNeasy PowerSoil Kit (QIAGEN, Germany). PCR was performed using the forward primer ${ }_{515} \mathrm{~F}$ (5'-GTGCCAGCMGCCGCGGTAA-3') and reverse primer 806R (5'-GGACTACHVGGGTWTCTAAT-3') to target the $\mathrm{V}_{4}$ region of $16 \mathrm{~S}$ rRNA gene (CAPORAso et al. 2011). The used primer and tag (unique molecular identifier for multiplexing) combinations for each sample are specified in Supplementary Table $S_{2}$. For PCR, the $25 \mu$ mixture per sample comprised of $2 \mu \mathrm{l}$ DNA ( $3 \mu$ for repeated samples), $0.5 \mu \mathrm{l}$ each of the primer $(10 \mu \mathrm{M}), 4 \mu \mathrm{l} 5 \times \mathrm{HOT}$ FirePol ${ }^{\circledR}$ Blend Master Mix (Solis BioDyne, Tartu, Estonia) and the rest of the volume was filled with sterile $\mathrm{dH}_{2} \mathrm{O}$. PCR was carried out in two replications in the following thermocycling conditions: an initial $15 \mathrm{~min}$ at $95^{\circ} \mathrm{C}$, followed by 35 cycles of $94^{\circ} \mathrm{C}$ for $45 \mathrm{~s}, 50^{\circ} \mathrm{C}$ for $60 \mathrm{~s}, 72^{\circ} \mathrm{C}$ for $90 \mathrm{~s}$, and a final cycle of $10 \mathrm{~min}$ at $72^{\circ} \mathrm{C}$. PCR products per sample were pooled and their relative quantity was estimated during gel electrophoresis of $5 \mu$ l DNA sample on $1 \%$ agarose gel. Based on gel band intensity, all PCR products were pooled at approximately equimolar concentration. The DNA library was purified using Favor-Prep ${ }^{\mathrm{TM}}$ Gel/PCR Purification Kit (Favorgen-Biotech Corp., Vienna, Austria), following the manufacturer's instructions. Sequencing was performed on an Illumina MiSeq instrument $(2 \times 250)$ using the MiSeq Reagent Kit v2. Steps of DNA extraction, PCR and sequencing included both negative and positive controls (Supplementary Table S2). Sequencing data (including control samples) have been deposited in the Sequence Read Archive (SRA): BioProject ID PRJNA533915.

\section{Bioinformatics}

The paired-end sequence data was processed in QIIME (v1.9.0; CAPORAso et al. 2010) using the Environmental Microbiome and Bioinformatic Analysis Platform of School of Public Health in Lanzhou University. Data analysis methods were as described previously (Li et al. 2016b). Briefly, paired-end sequences were joined using Flash soft- 
ware (v1.2.8; MAgoc \& SAlzberg 2011). Those sequences with length $<300 \mathrm{bp}$, average base quality score $<30$ or ambiguous bases, were removed for the downstream analysis. The Uchime algorithm (EDGAR et al. 2011) was used to filter out potential chimeric reads. The filtered sequences were clustered into operational taxonomic units (OTUs) at a $97 \%$ identity threshold using UCLUST algorithm (EDGAR 2010). Taxonomy was assigned using the Ribosomal Database Project classifier (WANG et al. 2007). OTUs not classifying to Bacteria, Eukaryota and Archaea lineages, were removed. Although Archaea may represent an important part of gut microbiome (RAYMANN et al. 2017), we removed this group from the analyses because of the low specificity of the used primers $(515 \mathrm{~F} / 806 \mathrm{R})$ to Archaea (BAHRAM et al. 2018a, RAYMAnN et al. 2017) (our data set contained $<0.001 \%$ of Archaea sequences). To account for the unequal sequencing depth, each sample was rarefied to the same number of reads $(5,654$ sequences). The latter led to discarding one of the frozen gut sample from the downstream analysis. The OTU table was further filtered to remove singleton OTUs and low-abundance read records of OTUs per sample (<10 reads). After these steps, cyanobacterial OTUs were removed from the analysis as these taxa likely do not represent true gut microbiota (e.g. Nostocophycideae, Synechococcophycideae, Oscillatoriophycideae (PAtzelt et al. 2014)). Additionally, taxa that were assigned to 'mitochondria', were also excluded from the analyses as potential mitochondrial reads of the host itself. The filtered OTU table used for the analyses is specified in Supplementary Table $\mathrm{S}_{3}$.

\section{Statistical analysis}

The effect of sample type (EtOH-stored feces, EtOH-stored gut and frozen gut) on log-transformed OTU richness and phylogenetic diversity (PD) were tested using KruskalWallis analysis. OTU richness correlation analyses between samples types were performed using Spearman rank correlation analysis. The effect of these factors on the bacterial OTU composition was analyzed using PERMANO$\mathrm{VA}+$ (ANDERSON 2005) with 9,999 permutations (Type III SS) in PRIMER v6 (ClARKe \& GoRley 2006). For the PERMANOVA analysis and non-metric multidimension- al scaling (NMDS) graphs, we used Hellinger-transformed Bray-Curtis as well as UniFrac distance (unweighted) OTU matrices. UniFrac distance and PD were calculated by applying the PhyloMeasures package (v2.1; Tsirogiannis \& SANDEL 2016) in R (R Core-Team 2020) using a Maximum-Likelihood based phylogenetic 16Sr RNA gene tree generated with RAxML (STAMATAKIS 2014). The similarity between Hellinger-transformed Bray-Curtis distance based NMDS ordinations of each sample type was tested using Procrustes analyses using the R-package 'vegan' (OKSANEN et al. 2015). We used indicator species analysis ('indicspecies' v1.7.6 package in R; De CACEREs et al. 2016) to determine which OTUs are significantly (using 9,999 permutations) associated with particular sample types. A Venn diagram of shared OTUs between sample types was created using mothur (SCHLOss et al. 2009).

\section{Results}

Our analysis comprised samples of 12 individual tadpoles (Fig. 1). Replicate samples of EtOH-stored feces, EtOHstored gut and frozen gut per specimen demonstrated significant (Kruskal-Wallis test: $\mathrm{P}<0.001)$ and high (3.8-fold) OTU richness variability (Supplementary Fig. S1). This pattern was driven by the frozen gut samples that exhibited significantly lower OTU richness and phylogenetic diversity (PD) values as compared to the other samples (Figs 2ab). Consequently, there was no strong positive sample by sample correlation of the detected OTU richness between frozen gut and other treatments (Spearman $\mathrm{R}=0.179, \mathrm{P}=$ 0.599 for gut (EtOH) vs. gut (frozen); Spearman $\mathrm{R}=-0.378$, $\mathrm{P}=0.251$ for feces (EtOH) vs. gut (frozen); Supplementary Fig. S2). This correlation was highest between EtOH preserved samples (gut vs. feces; Spearman R = 0.494), however, the association was statistically non-significant $(\mathrm{P}=$ o.103; Supplementary Fig. S2).

The communities of detected microbiota were significantly different between sample types (PERMANOVA $\mathrm{P}<$ 0.001; Table 1; Figs 2c-d; Fig. 3). EtOH-stored samples vs. frozen gut samples demonstrated to harbor low proportions of shared OTUs, $14.1 \%$ and $15.6 \%$ (Fig. 4) for $\mathrm{EtOH}$-stored gut vs. frozen and $\mathrm{EtOH}$-stored feces vs. frozen gut samples, respectively. Accordingly, based on the

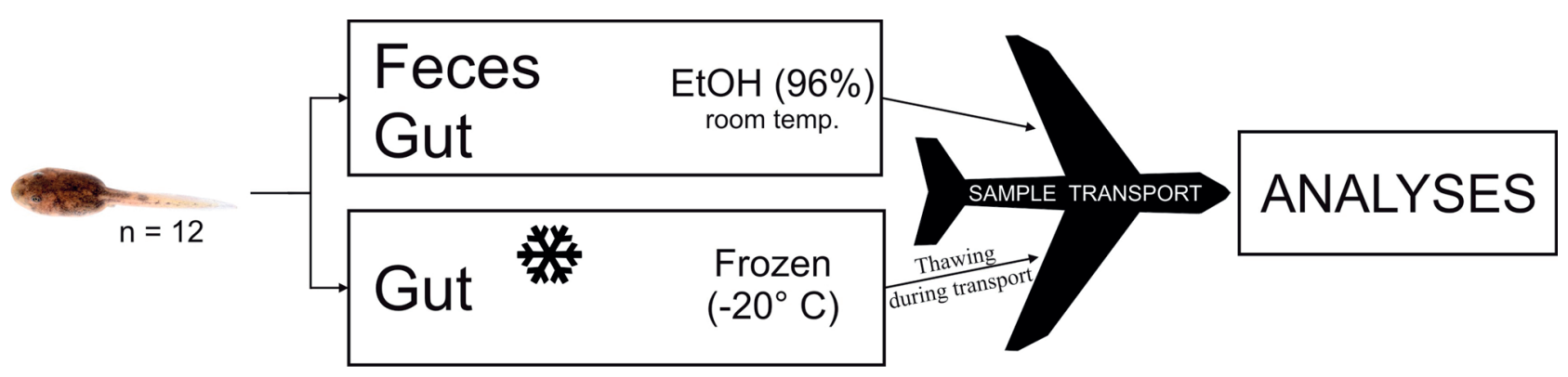

Figure 1. Illustration of the study design. Three treatments: ethanol (EtOH) stored feces and gut, and frozen gut samples of Nanorana parkeri. Note that the frozen samples went through thawing episodes during sample transport from the field to the laboratory. 
Table 1. PERMANOVA results for Nanorana parkeri samples with factor sample type (EtOH-stored feces, EtOH-stored gut and frozen gut). PW denote pairwise comparison between EtOHstored gut and frozen gut (PW1), EtOH-stored feces and frozen gut (PW2), EtOH-stored feces and EtOH-stored gut (PW3) samples.

\begin{tabular}{lccccr}
\hline OTU matrix & $\mathrm{R}_{\text {adj }}^{2}$ & $\mathrm{P}$ & $\mathrm{P}, \mathrm{PW} 1$ & $\mathrm{P}, \mathrm{PW} 2$ & $\mathrm{P}, \mathrm{PW}$ \\
\hline Bray-Curtis & 0.470 & $<0.001$ & $<0.001$ & $<0.001$ & $<0.001$ \\
Unifrac & 0.361 & $<0.001$ & $<0.001$ & $<0.001$ & 0.007 \\
\hline
\end{tabular}

Procrustes analyses, the pairwise comparisons of the latter sample types showed the highest differences (i.e. weakest Procrustes correlation) with the correlation values of
$0.346(\mathrm{P}=0.474)$ and $0.370(\mathrm{P}=0.370)$ for EtOH-stored gut vs. frozen gut and $\mathrm{EtOH}$-stored feces vs. frozen gut samples, respectively. The highest similarity, but marginally non-significant Procrustes correlation was observed between $\mathrm{EtOH}$-stored feces and $\mathrm{EtOH}$-stored gut samples (Procrustes correlation $=0.523, \mathrm{P}=0.072$ ) . The proportion of shared OTUs between the latter sample types was $26.2 \%$ (Fig. 4).

Indicator species analysis revealed a large number of OTUs that were differentially abundant in across samples; 13 OTUs for EtOH-stored feces, 28 OTUs for EtOH-stored gut (30 OTUs for the combination of EtOH-stored samples) and 12 OTUs for the frozen gut samples (Supplementary Table $\left.\mathrm{S}_{4}\right)$. The combination of EtOH-stored samples (feces + gut) harbored many indicator OTUs, whereas
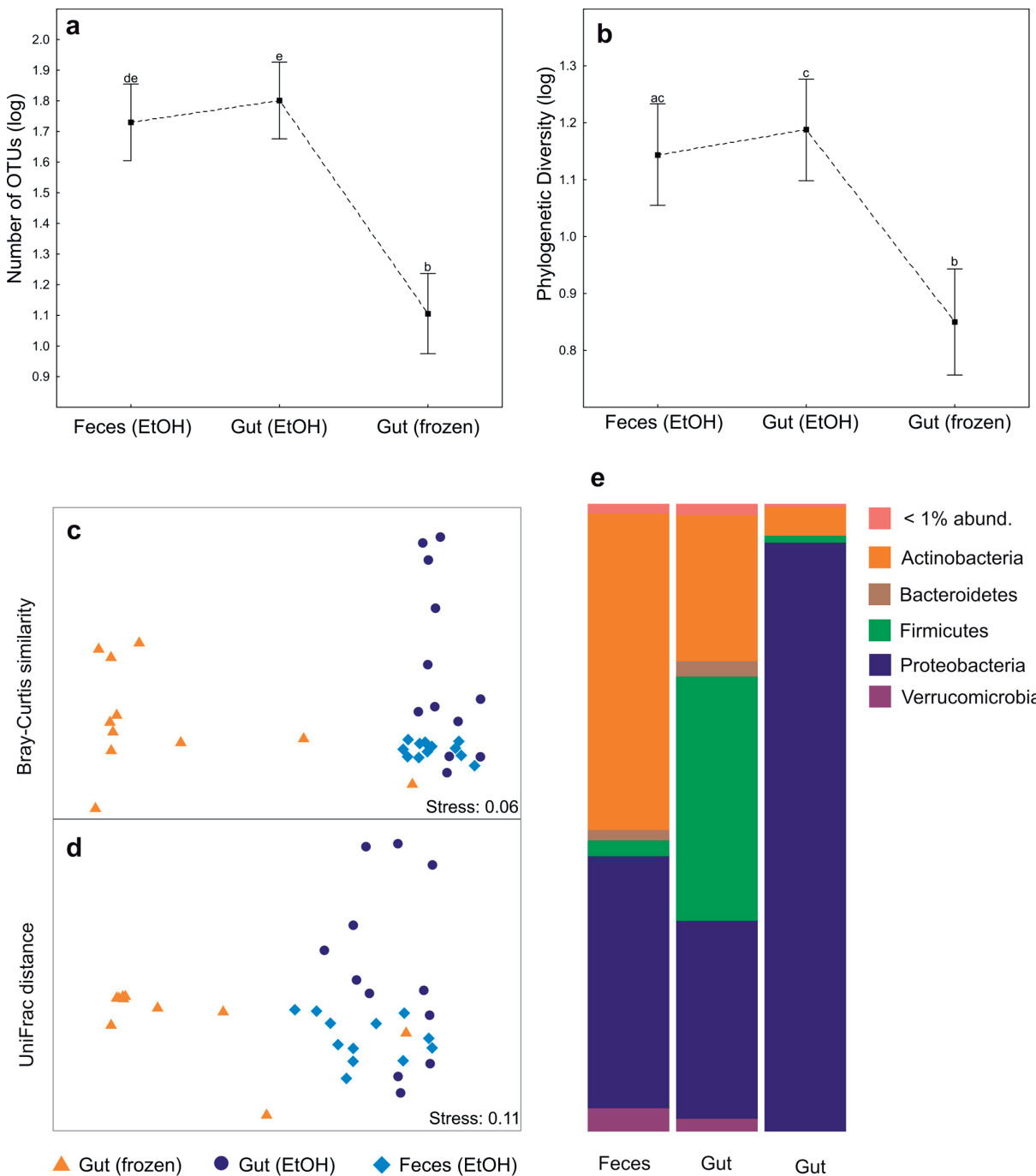

e

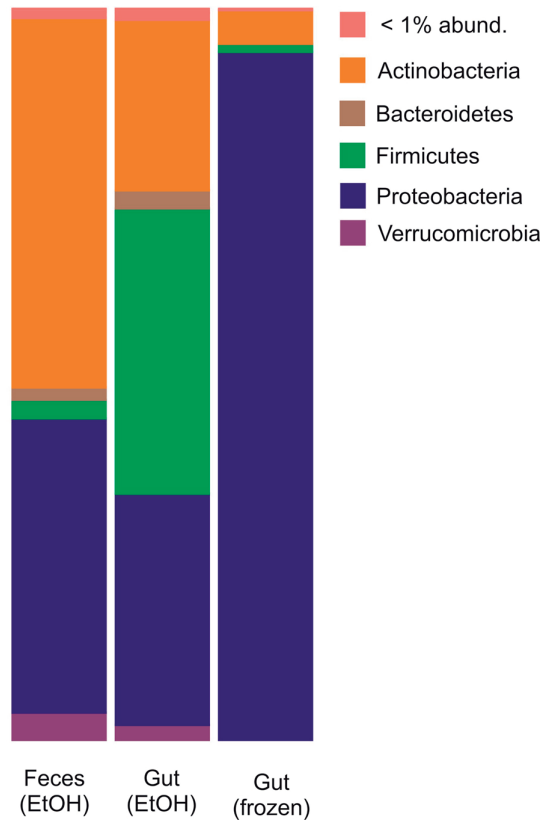

Figure 2. a) OTU richness (log transformed) and b) phylogenetic diversity (log transformed) for EtOH-stored feces, EtOH-stored gut and frozen gut samples of Nanorana parkeri. Whiskers denote $95 \%$ confidence intervals. Different letter combinations on top of whiskers denote significant difference between groups $(\alpha<0.05)$ as based on Tukey HSD test. c, d) NMDS graphs as based on BrayCurtis similarity and UniFrac distance of bacterial community composition. e) Bar plots showing relative abundance of reads assigned to bacterial phyla, summarized for each treatment. 
no OTUs were assigned to be specific for sample combinations with frozen gut samples (i.e. EtOH-stored feces + frozen gut, EtOH-stored gut + frozen gut) (Supplementary Table $\mathrm{S}_{4}$ ). This further suggests an overall higher similarity of the two types of EtOH-stored samples, which is also evident from the NMDS graphs (Figs $2 \mathrm{c}-\mathrm{d}$ ).

Frozen gut samples showed a consistent increase of Proteobacteria (sequence abundance; Fig. 2e), which was mainly caused by ten of the indicator OTUs, all belonging to the Gammaproteobacteria: two undetermined Aeromonadaceae, two undetermined Enterobacteriaceae, two Klebsiella (Enterobacteriaceae), two Pseudomonas (Pseudomonadaceae), and two Shewanella (Shewanellaceae). These OTUs represented a very high proportion of reads in the frozen gut samples (90.1\%), but most of them were completely absent from all of the other sample types. EtOH-stored gut samples, however, showed highest relative abundance of Firmicutes (sequence abundance; Fig. 2e). This pattern was particularly driven by Clostridia of which 25 OTUs were identified as indicators, and thus were relatively more abundant in the gut $(\mathrm{EtOH})$ samples (Supplementary Table $\mathrm{S}_{4}$ ), forming $26.4 \%$ of the reads on EtOH-stored gut samples.

\section{Discussion}

As the number of DNA sequences of environmental or host-associated samples in public databases increase and acquiring such data becomes a routine approach in microbial ecology, meta-analyses of comprehensive "big data" sets is becoming a promising research direction, leading to important insights into general patterns of bacterial diversity (ADAms et al. 2015, GonZALEZ et al. 2018, RocCA et al. 2018, Kueneman et al. 2019). However, considering the many technical factors influencing the outcome of amplicon analyses, including sample preservation, DNA extraction, PCR conditions and sequencing methods (GOODRICH et al. 2014, Clooney et al. 2016, ANSLAN et al. 2018), it is of high importance to ascertain that such meta-analyses indeed recover biological patterns and not methodological differences among studies.

Our study exemplifies that the recovery of host-associated microbiota richness and community structure may vary among sampling substrates. The two EtOH-stored substrates, gut content recovered by dissection and fecal samples, overall, revealed rather consistent patterns of OTU richness and phylogenetic diversity. However, considering community composition, important differences between gut and fecal samples were apparent, where

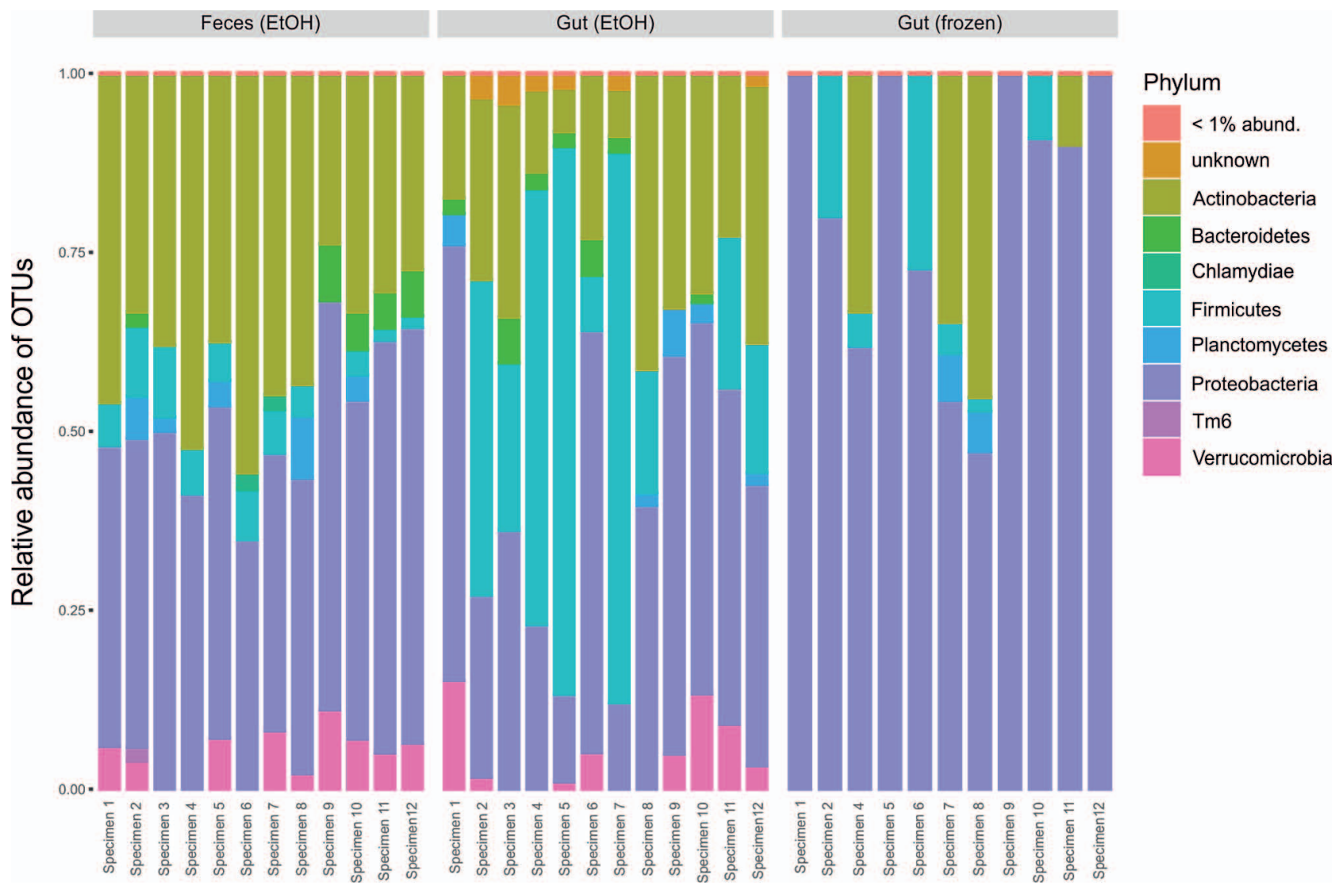

Figure 3. Relative abundance of bacterial OTUs in all samples. 
only about one fourth of the OTUs was shared between these sample types (Fig. 4). Similarly, ZHOU et al. (2020) recently reported that the microbial composition from fecal samples of adult cane toads (Rhinella marina) were significantly different from the intestine (gut) samples. Similar results were found by GRIFFIN et al. (2020) by studing blue mussels (Mytilus edulis), where they discourage the use of fecal samples to explore the gut microbial communities. One factor affecting the community difference between gut and feces could be the exposure to oxygen upon leaving the intestinal tract (RAGo et al. 2017). Although we included a pond water control in our study to account for external contamination, the exposure to environmental contamination of fecal samples may further have facilitated the changes in microbial composition associated with feces samples (Song et al. 2018, Griffin et al. 2020). In this study and previous studies by ZHOU et al. (2020) and Griffin et al. (2020), a single DNA extraction method was applied, but by utilizing two different DNA extracion methods to study the gut microbiota of the Asiatic toad tadpoles (Bufo gargarizans), SoNG et al. (2018) reported contrasting results. The results from samples subjected to TIANamp stool DNA kit demonstrated significant differences between gut and feces, but interestingly, samples subjected to phenol-chloroform DNA extraction exhibited consistent microbial community composition patterns between these two sample types. Based on these results, the authors suggested that feces of amphibian tadpoles may be effectively used to study their gut microbiota. This high-

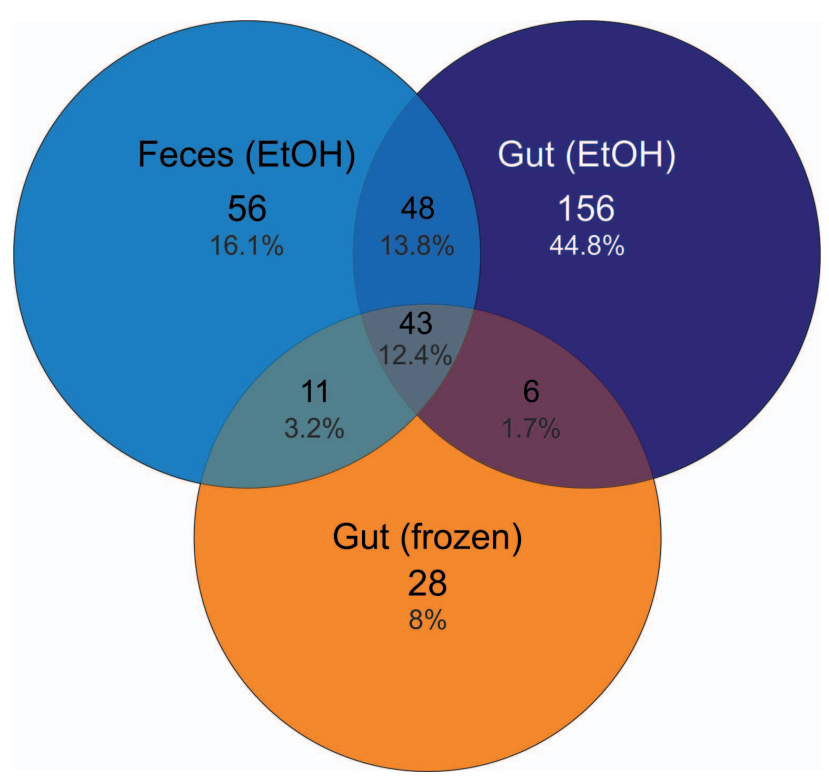

Figure 4. Venn diagram of shared OTUs between sample types. Total number of OTUs is 348 . The number of OTUs in feces (EtOH), gut (EtOH) and gut (frozen) samples is 158, 253 and 88, respectively. The number of shared OTUs between feces (EtOH) and gut (EtOH) is 91 (26.2\%). The number of shared OTUs between feces (EtOH) and gut (frozen) samples is 54 (15.6\%), and $49(14.1 \%)$ between gut (EtOH) and gut (frozen) samples. Total numbers of shared OTUs is $43(12.4 \%)$. lights also the effect of DNA extraction method on the recovered microbial composition, which has been reported in several other studies (e.g. Chapagain et al. 2019, FiEDorova et al. 2019). Althogether, it is obvious that merging results based on these different types of substrates (gut and feces) for a meta-analyses may introduce biases, and thus they should be combined with great caution, and only when large differences between hosts are expected (which then would override the influences of methodology and substrate).

An even more divergent pattern was found between commonly used sample preservation methods (EtOH vs. freezing), with enormous differences both in bacterial richness and community structure. Consistently, in almost all individual tadpole (frozen) gut samples, Proteobacteria had enormously increased relative abundances, whereas relative abundances of Firmicutes and Verrucomicrobia were much lower (Fig. 2e; Fig. 3) compared to the EtOH-preserved samples. As summarized by КонL (2017), blooming of certain taxa can change the composition of gut or fecal bacterial communities (CHOO et al. 2015, BECKERS et al. 2017). We hypothesize this is what happened in our samples upon thawing periods during sample transport. The blooming hypothesis is also supported by the fact that the Proteobacteria increase was caused by a limited number of bacterial OTUs, and most strongly influenced by only seven OTUs. Moreover, these OTUs were totally absent from the EtOH-stored Nanorana gut samples. However, several studies on soil, human- and insect-associated microbiomes have revealed that differences among preservation methods are smaller than those between taxa and individuals, thus validating meta-analyses based on differently stored samples (LAUBER et al. 2010, Dominianni et al. 2014, HAmmer et al. 2015, BlekHMAN et al. 2016, Song et al. 2016). A study about sample preservation methods of fecal microbiota of spider monkeys revealed that the microbial community composition of EtOH-stored and frozen samples were similar to fresh ones (HALE et al. 2015). Thus, it is expected that the latter sample storing methods are producing comparable results. Furthermore, a study on insect-associated microbiomes has suggested that the sample storage method (freezing, ethanol, dimethyl sulfoxide, cetrimonium bromide, storage without any preservative) has no or minor effect on microbiome composition (HAMMER et al. 2015). However, under typical field sampling conditions, such as in this study, continuous deep-freezing of samples cannot be always ensured, which implies the possibility of radical effects on gut microbiomes. Sampling ungulate feces in the wild, Menke et al. (2015) observed only moderate shifts of the microbiome during 2-4 days but radical changes afterwards, usually following rain. On the contrary, BECKERs et al. (2017) observed an important decrease in bacterial diversity in horse feces already after approximately 4 hours. A significant decrease of Bacteroidetes has been reported from fecal samples (of humans and monkeys) exposed to room temperature or to natural environmental conditions (RoescH et al. 2009, HALE et al. 2016), which we also found to be the case for the frozen 
samples that were exposed to thawing in current study. Our study confirms that in certain cases, a rise of "bloom" bacteria can completely obscure the original microbiome composition in the samples, and several bacterial families might be particularly prone to contain such rapid growth taxa; for instance, Enterobacteriaceae and Pseudomonadaceae were associated with microbiome shifts both in this study and in that of BECKERs et al. (2017).

\section{Conclusion}

Our case study confirms that both substrate (gut content vs. feces) and preservation method can influence the analysis of intestinal microbiomes, and provides an example from tadpoles. Differences between substrates and preservation methods are here shown for samples from exactly the same individuals, sampled at the same time point, thus excluding these factors that might influence microbiome structure. Although non-invasive collection of feces may be preferred over dissection for ethical reasons, it is important to acknowledge the recovery of potentially different microbiome communities between these treatments, as demonstrated in this study. When using fecal samples, one must be also aware of environmental contaminations of these samples, which could be minimized by collecting control samples in the immediate environment. Although the latter was attempted in our study, significant differences between microbial composition of gut and feces were still obvious. Emphasizing the thawing cycles of frozen samples, the strongest differences were found between preservation methods and demonstrate that blooming of contaminant taxa can completely distort the bacterial community in samples of intestinal microbiome of aquatic vertebrates, within only a few hours of thawing as it is common under field conditions.

\section{Acknowledgments}

We are indebted to numerous colleagues, in particular MAGNUS Asmussen, Nicole Börner, Andrew Henderson, Wengang Kang, ANTje Schwalb, and Anja Schwarz for their help during fieldwork; and to the team of the NAMORS station of the Institute of Tibetan Plateau Research of the Chinese Academy of Sciences, in particular GUANGJIAN WU, for logistic support. SA and MV were funded through the Deutsche Forschungsgemeinschaft (DFG; grant 317513741) via the International Research Training Group 2309, "Geoecosystems in transition on the Tibetan Plateau" (TransTiP). The permission for the study was obtained via Institute of Tibetan Plateau Research (Chinese Academy of Sciences) from Tibet Autonomous Region Government (issued on 19 June 2018).

\section{References}

Adams, R. I., A. C. Bateman, H. M. Bik \& J. F. Meadow (2015): Microbiota of the indoor environment: A meta-analysis. Microbiome, 3: 49 .
Amend, A. S., T. A. Oliver, L. A. Amaral-Zettler, A. Boetius, J. A. Fuhrman, M. C. Horner-Devine, S. M. Huse, D. B. M. Welch, A. C. Martiny \& A. Ramette (2013): Macroecological patterns of marine bacteria on a global scale. - Journal of Biogeography, 40: 800-811.

Anderson, M. J. (2005): Permutational multivariate analysis of variance. - University of Auckland, Auckland.

Anslan, S., R. H. Nilsson, C. Wurzbacher, P. Baldrian, L. Tedersoo \& M. BAhram (2018): Great differences in performance and outcome of high-throughput sequencing data analysis platforms for fungal metabarcoding. - MycoKeys, 39: 29-40.

Bahram, M., S. Anslan, F. Hildebrand, P. Bork \& L. Tedersoo (2018a): Newly designed 16s rRNA metabarcoding primers amplify diverse and novel archaeal taxa from the environment. - Environmental Microbiology Reports, 11: 487-494.

Bahram, M., F. Hildebrand, S. K. Forslund, J. L. Anderson, N. A. Soudzilovskaia, P. M. Bodegom, J. BengtssonPalme, S. Anslan, L. P. Coelho \& H. Harend (2018b): Structure and function of the global topsoil microbiome. - Nature, 560: 233-237.

Beckers, K. F., C. J. Schulz \& G. W. Childers (2017): Rapid regrowth and detection of microbial contaminants in equine fecal microbiome samples. - PLoS ONE, 12: e0187044.

Blekhman, R., K. Tang, E. A. Archie, L. B. Barreiro, Z. P. Johnson, M. E. Wilson, J. Kohn, M. L. Yuan, L. Gesquiere \& L. E. GRIENEISEN (2016): Common methods for fecal sample storage in field studies yield consistent signatures of individual identity in microbiome sequencing data. - Scientific Reports, 6: 31519 .

Bletz, M. C., D. J. Goedbloed, E. Sanchez, T. Reinhardt, C. C. Tebbe, S. Bhuju, R. Geffers, M. Jarek, M. Vences \& S. Steinfartz (2016): Amphibian gut microbiota shifts differentially in community structure but converges on habitatspecific predicted functions. - Nature Communications, 7: 13699.

Bletz, M. C., A. H. Loudon, M. H. Becker, S. C. Bell, D. C. Woodhams, K. P. Minbiole \& R. N. Harris (2013): Mitigating amphibian chytridiomycosis with bioaugmentation: Characteristics of effective probiotics and strategies for their selection and use. - Ecology Letters, 16: 807-820.

Caporaso, J. G., J. Kuczynski, J. Stombaugh, K. Bittinger, F. D. Bushman, E. K. Costello, N. Fierer, A. G. Peña, J. K. GOODRICH \& J. I. GORDON (2010): Qiime allows analysis of high-throughput community sequencing data. - Nature Methods, 7: 335-336.

Caporaso, J. G., C. L. Lauber, W. A. Walters, D. Berg-Lyons, C. A. Lozupone, P. J. Turnbaugh, N. Fierer \& R. Knight (2011): Global patterns of $16 \mathrm{~s}$ rRNA diversity at a depth of millions of sequences per sample. - Proceedings of the National Academy of Sciences, 108: 4516-4522.

Chapagain, P., B. Arivett, B. M. Cleveland, D. M. Walker \& M. SAlEM (2019): Analysis of the fecal microbiota of fast-and slow-growing rainbow trout (Oncorhynchus mykiss). - BMC Genomics, 20: 788 .

Choo, J. M., L. E. Leong \& G. B. Rogers (2015): Sample storage conditions significantly influence faecal microbiome profiles. - Scientific Reports, 5: 16350.

Clarke, K. \& R. Gorley (2006): Primer v6: User manual/tutorial. - Primer-E Ltd. Plymouth, 192 pp. 
Clemente, J. C., L. K. Ursell, L. W. Parfrey \& R. Knight (2012): The impact of the gut microbiota on human health: An integrative view. - Cell, 148: 1258-1270.

Clooney, A. G., F. Fouhy, R. D. Sleator, A. O’Driscoll, C. Stanton, P. D. Cotter \& M. J. Claesson (2016): Comparing apples and oranges?: Next generation sequencing and its impact on microbiome analysis. - PLoS ONE, 11: e0148028.

De Caceres, M., F. Jansen \& M. M. De Caceres (2016): Package 'indicspecies', ver. 1.7.6. - https://cran.r-project.org/web/packages/indicspecies/index.html.

Dominianni, C., J. Wu, R. B. Hayes \& J. Ahn (2014): Comparison of methods for fecal microbiome biospecimen collection. - BMC Microbiology, 14: 103.

EDGAR, R. C. (2010): Search and clustering orders of magnitude faster than blast. - Bioinformatics, 26: 2460-2461.

Edgar, R. C., B. J. Haas, J. C. Clemente, C. Quince \& R. KNIGHT (2011): Uchime improves sensitivity and speed of chimera detection. - Bioinformatics, 27: 2194-2200.

Engel, P. \& N. A. Moran (2013): The gut microbiota of insectsdiversity in structure and function. - FEMS Microbiology Reviews, 37: 699-735.

Ericsson, A. C., J. Gagliardi, D. Bouhan, W. G. Spollen, S. A. Givan \& C. L. Franklin (2018): The influence of caging, bedding, and diet on the composition of the microbiota in different regions of the mouse gut. - Scientific Reports, 8: 4065.

Falony, G., S. Vieira-Silva \& J. Raes (2018): Richness and ecosystem development across faecal snapshots of the gut microbiota. - Nature Microbiology, 3: 526-528.

Fiedorová, K., M. RAdVANSKÝ, E. NĚMCOVÁ, H. GrombiříKovÁ, J. Bosák, M. Černochová, M. Lexa, D. Šmajs \& T. FreiBERGER (2019): The impact of DNA extraction methods on stool bacterial and fungal microbiota community recovery. Frontiers in Microbiology, 10: 821.

Fontaine, S. S., A. J. Novarro \& K. D. Kohl (2018): Environmental temperature alters the digestive performance and gut microbiota of a terrestrial amphibian. - Journal of Experimental Biology, 221: jeb187559.

Fricker, A. M., D. Podlesny \& W. F. Fricke (2019): What is new and relevant for sequencing-based microbiome research? A minireview. - Journal of Advanced Research, 19: 105-112.

Griffin, T. W., J. G. BAer \& J. E. WARD (2020): Direct comparison of fecal and gut microbiota in the blue mussel (Mytilus edulis) discourages fecal sampling as a proxy for resident gut community. - Microbial Ecology, in press.

Gonzalez, A., J. A. Navas-Molina, T. Kosciolek, D. McDonald, Y. Vázquez-Baeza, G. Ackermann, J. DeReus, S. JansSEN, A. D. SWAFFord \& S. B. OrChanian (2018): Qiita: Rapid, web-enabled microbiome meta-analysis. - Nature Methods, 15: $796-798$.

Goodrich, J. K., S. C. Di Rienzi, A. C. Poole, O. Koren, W. A. Walters, J. G. Caporaso, R. Knight \& R. E. Ley (2014): Conducting a microbiome study. - Cell, 158: 250-262.

Gosner, K. L. (1960): A simplified table for staging anuran embryos and larvae with notes on identification. - Herpetologica, 16: $183-190$

Hale, V. L., C. L. Tan, R. Knight \& K. R. Amato (2015): Effect of preservation method on spider monkey (Ateles geoffroyi) fecal microbiota over 8 weeks. - Journal of Microbiological Methods, 113: 16-26.
Hale, V. L., C. L. Tan, K. Niu, Y. Yang, D. Cui, H. Zhao, R. KNight \& K. R. Амato (2016): Effects of field conditions on fecal microbiota. - Journal of Microbiological Methods, 130: $180-188$.

Hammer, T. J., J. C. Dickerson \& N. Fierer (2015): Evidencebased recommendations on storing and handling specimens for analyses of insect microbiota. - PeerJ, 3: e119o.

Huang, B.-H., C.-W. Chang, C.-W. Huang, J. Gao \& P.-C. Liao (2018): Composition and functional specialists of the gut microbiota of frogs reflect habitat differences and agricultural activity. - Frontiers in Microbiology, 8: 2670.

Knutie, S. A., C. L. Wilkinson, K. D. Kohl \& J. R. Rohr (2017): Early-life disruption of amphibian microbiota decreases laterlife resistance to parasites. - Nature Communications, 8: 86.

KoHL, K. D. (2017): An introductory "how-to" guide for incorporating microbiome research into integrative and comparative biology. - Integrative and Comparative Biology, 57: 674-681.

Kohl, K. D., J. Amaya, C. A. Passement, M. D. Dearing \& M. D. McCue (2014): Unique and shared responses of the gut microbiota to prolonged fasting: A comparative study across five classes of vertebrate hosts. - FEMS Microbiology Ecology, 90: $883-894$.

Kohl, K. D., T. L. Cary, W. H. Karasov \& M. D. Dearing (2013): Restructuring of the amphibian gut microbiota through metamorphosis. - Environmental Microbiology Reports, 5: 899903.

Kueneman, J. G., M. C. Bletz, V. J. McKenzie, C. G. Becker, M. B. Joseph, J. G. Abarca, H. Archer, A. L. Arellano, A. BATAILlE \& M. BeCKer (2019): Community richness of amphibian skin bacteria correlates with bioclimate at the global scale. - Nature Ecology \& Evolution, 3: 381-389.

Lauber, C. L., N. Zhou, J. I. Gordon, R. Knight \& N. Fierer (2010): Effect of storage conditions on the assessment of bacterial community structure in soil and human-associated samples. - FEMS Microbiology Letters, 307: 80-86.

Li, H., T. Li, M. YaO, J. Li, S. Zhang, S. Wirth, W. CaO, Q. Lin \& X. LI (2016a): Pika gut may select for rare but diverse environmental bacteria. - Frontiers in Microbiology, 7: 1269.

LI, H., J. QU, T. LI, J. LI, Q. LIN \& X. LI (2016b): Pika population density is associated with the composition and diversity of gut microbiota. - Frontiers in Microbiology, 7: 758.

Lyra, M. L., M. C. Bletz, C. F. B. Haddad \& M. Vences (2018): The intestinal microbiota of tadpoles differs from those of syntopic aquatic invertebrates. - Microbial Ecology, 76: 121-124.

Magoc, T. \& S. L. SAlzberg (2011): Flash: Fast length adjustment of short reads to improve genome assemblies. - Bioinformatics, 27: 2957-2963.

McFall-Ngai, M., M. G. Hadfield, T. C. Bosch, H. V. Carey, T. Domazet-Lošo, A. E. Douglas, N. Dubilier, G. Eberl, T. FukAMi \& S. F. Gilbert (2013): Animals in a bacterial world, a new imperative for the life sciences. - Proceedings of the $\mathrm{Na}$ tional Academy of Sciences, 110: 3229-3236.

McKenzie, V. J., R. M. Bowers, N. Fierer, R. Knight \& C. L. LAUBER (2012): Co-habiting amphibian species harbor unique skin bacterial communities in wild populations. - The ISME Journal, 6: 588 .

Menke, S., M. Meier \& S. Sommer (2015): Shifts in the gut microbiome observed in wildlife faecal samples exposed to natural weather conditions: Lessons from time-series analyses using 
next-generation sequencing for application in field studies. Methods in Ecology and Evolution, 6: 1080-1087.

Oksanen, J., F. G. Blanchet, R. Kindt, P. Legendre, P. R. Minchin, R. O'hara, G. L. Simpson, P. Solymos, M. SteVENS \& H. WAGNeR (2015): Vegan: Community ecology package, ver. 2.4-2. - https://cran.r-project.org/web/packages/vegan/index.html

Patzelt, D. J., L. Hodač, T. Friedl, N. Pietrasiak \& J. R. JoHANSEN (2014): Biodiversity of soil cyanobacteria in the hyper-arid atacama desert, chile. - Journal of Phycology, 50: 698-710.

R Core-Team (2020): R: A language and environment for statistical computing. - The R Foundation for Statistical Computing, Vienna, Austria. http://www.R-project.org/.

Rago, L., P. Cristiani, F. Villa, S. Zecchin, A. Colombo, L. Cavalca \& A. Schievano (2017): Influences of dissolved oxygen concentration on biocathodic microbial communities in microbial fuel cells. - Bioelectrochemistry, 116: 39-51.

Raymann, K., A. H. Moeller, A. L. Goodman \& H. Ochman (2017): Unexplored archaeal diversity in the great ape gut microbiome. - mSphere, 2: eooo26-00017.

Reese, A. T. \& R. R. Dunn (2018): Drivers of microbiome biodiversity: A review of general rules, feces, and ignorance. mBio, 9: e01294-01218.

Rocca, J. D., M. Simonin, J. R. BlaszczaK, J. G. Ernakovich, S. M. Gibbons, F. S. Midani \& A. D. Washburne (2018): The microbiome stress project: Toward a global meta-analysis of environmental stressors and their effects on microbial communities. - Frontiers in Microbiology, 9: 3272.

Roesch, L. F., G. Casella, O. Simell, J. Krischer, C. H. Wasserfall, D. Schatz, M. A. Atkinson, J. Neu \& E. W. TripLETT (2009): Influence of fecal sample storage on bacterial community diversity. - The Open Microbiology Journal, 3: 40.

Round, J. L. \& S. K. MAzmanian (2009): The gut microbiota shapes intestinal immune responses during health and disease. - Nature Reviews Immunology, 9: 313.

Schloss, P. D., S. L. Westcott, T. Ryabin, J. R. Hall, M. HaRTmann, E. B. Hollister, R. A. Lesniewski, B. B. OAKley, D. H. Parks, C. J. Robinson, J. W. Sahl, B. Stres, G. G. ThalLINGER, D. J. VAN HORN \& C. F. Weber (2009): Introducing mothur: Open-source, platform-independent, communitysupported software for describing and comparing microbial communities. - Applied and Environmental Microbiology, 75: 7537-7541.

ShapIRA, M. (2016): Gut microbiotas and host evolution: Scaling up symbiosis. - Trends in Ecology \& Evolution, 31: 539-549.

Sommer, F. \& F. BÄCKHed (2013): The gut microbiota-masters of host development and physiology. - Nature Reviews Microbiology, 11: 227.

Song, S. J., A. Amir, J. L. Metcalf, K. R. Amato, Z. Z. Xu, G. Humphrey \& R. Knight (2016): Preservation methods differ in fecal microbiome stability, affecting suitability for field studies. - mSystems, 1: eooo21-0oo16.

Song, X., J. Song, H. Song, Q. Zeng \& K. Shi (2018): A robust noninvasive approach to study gut microbiota structure of amphibian tadpoles by feces. - Asian Herpetological Research, 9: 1-12G.

Sonnenburg, E. D., S. A. Smits, M. Tikhonov, S. K. Higginвотtom, N. S. Wingreen \& J. L. Sonnenburg (2016): Diet- induced extinctions in the gut microbiota compound over generations. - Nature, 529: 212.

STAMATAKIS, A. (2014): Raxml version 8: A tool for phylogenetic analysis and post-analysis of large phylogenies. - Bioinformatics, 30: 1312-1313.

Tremaroli, V. \& F. BÄCKhed (2012): Functional interactions between the gut microbiota and host metabolism. - Nature, 489: 242.

Tsirogiannis, C. \& B. SANDEL (2016): Phylomeasures: A package for computing phylogenetic biodiversity measures and their statistical moments. - Ecography, 39: 709-714.

Tuddenham, S. \& C. L. Sears (2015): The intestinal microbiome and health. - Current Opinion in Infectious Diseases, 28: 464.

Vences, M., M. L. Lyra, J. G. Kueneman, M. C. Bletz, H. M. Archer, J. Canitz, S. Handreck, R.-D. Randrianiaina, U. Struck, S. Bhuju, M. Jarek, R. Geffers, V. J. McKenzie, C. C. Tebbe, C. F. B. Haddad \& J. Glos (2016): Gut bacterial communities across tadpole ecomorphs in two diverse tropical anuran faunas. - The Science of Nature, 103: 25.

WALKe, J. B. \& L. K. Belden (2016): Harnessing the microbiome to prevent fungal infections: Lessons from amphibians. - PLoS PATHOGENS, 12: e1005796.

Wang, Q., G. M. Garrity, J. M. Tiedje \& J. R. Cole (2007): Naive bayesian classifier for rapid assignment of rRNA sequences into the new bacterial taxonomy. - Applied and Environmental Microbiology, 73: 5261-5267.

Weng, F. C.-H., Y.-J. YANG \& D. WANG (2016): Functional analysis for gut microbes of the brown tree frog (Polypedates megacephalus) in artificial hibernation. - BMC Genomics, 17: 1024.

Wiebler, J. M., K. D. Kohl, R. E. Lee JR \& J. P. Costanzo (2018): Urea hydrolysis by gut bacteria in a hibernating frog: Evidence for urea-nitrogen recycling in amphibia. - Proceedings of the Royal Society B: Biological Sciences, 285: 20180241.

Zhou, J., T. M. Nelson, C. Rodriguez Lopez, R. R. Sarma, S. J. Zhou \& L. A. Rollins (2020): A comparison of nonlethal sampling methods for amphibian gut microbiome analyses. Molecular Ecology Resources, 20: 844-855.

Zierer, J., M. A. Jackson, G. Kastenmüller, M. Mangino, T. Long, A. Telenti, R. P. Mohney, K. S. Small, J. T. Bell \& C. J. Steves (2018): The fecal metabolome as a functional readout of the gut microbiome. - Nature Genetics, 50: 790.

\section{Supplementary materials}

The following data are available online:

Supplementary Figure S1. OTU richness of each replicate sample per specimen.

Supplementary Figure S2. Correlation scatterplots of OTU richness (log transformed) for each sample type.

Supplementary Table S1. Bacterial OTUs that were identified from pond water control sample.

Supplementary Table S2. Used primer combinations.

Supplementary Table S3. Table of bacterial OTUs by samples used for the analyses.

Supplementary Table S4. Bacterial indicator OTUs per treatment (or combination of treatments) of Nanorana parkeri samples. 